\title{
Synthesis of indoles via alkylidenation of acyl hydrazides
}

\author{
Kevin Hisler, Aurélien G. J. Commeureuc, Sheng-ze Zhou, John A. Murphy* \\ WestCHEM, Department of Pure and Applied Chemistry, University of Strathclyde, Thomas Graham Building, 295 Cathedral Street, Glasgow G1 1XL, United Kingdom
}

\section{A R T I C L E I N F O}

\section{Article history:}

Received 10 January 2009

Revised 25 January 2009

Accepted 9 February 2009

Available online 13 February 2009

\begin{abstract}
A B S T R A C T
Indoles have been synthesised via alkylidenation of acyl phenylhydrazides using phosphoranes and the Petasis reagent, followed by in situ thermal rearrangement of the product enehydrazines. The Petasis reagent provides an essentially neutral equivalent of the [acid-catalysed] Fischer indole synthesis, but with acyl phenylhydrazides as starting substrates. Alkylidene triphenylphosphoranes convert aroyl phenylhydrazides to indoles, but acyl phenylhydrazides derived from aliphatic carboxylic acids undergo a Brunner reaction to form indolin-2-ones.
\end{abstract}

(c) 2009 Elsevier Ltd. All rights reserved.
The indole ring system is a crucial structure in drug discovery, and has become an essential component in many pharmacologically active compounds. The extensive number of synthetic routes to and applications of indoles emphasises the great interest in this area. While a wide range of methods exist, significant efforts have been made to provide syntheses under mild reaction conditions, which tolerate a wide range of functional groups and start from readily available substrates. ${ }^{1,2}$

The most commonly used method for the preparation of indoles remains the Fischer indole synthesis discovered in $1883 .^{3,4}$ In spite of extensive studies, important efforts are still focussed on providing synthetic routes under mild conditions and with good regiocontrol on the outcome of the reaction. 5,6

Our current approach to indoles arises from our recently reported alkylidenation of Weinreb amides $\mathbf{1}^{7,8}$ in non-classical Wittig reactions. ${ }^{9,10}$ The expected initial products, enamines $\mathbf{2}$, were not isolated, but instead underwent easy hydrolysis to ketones and aldehydes 3. These transformations make use of the enhanced reactivity of the Weinreb amide carbonyl group as an electrophile, due to the inductive effect of the methoxy oxygen atom.

This reaction extends the scope of the Wittig reaction, and provides alternative routes to ketones and aldehydes from Weinreb amides without the use of organometallic reagents.

Success in that study led us to investigate the reactivity of Wittig reagents with acyl hydrazides 4 . While expected to be less reactive than the Weinreb amides, the hydrazides $\mathbf{4}$ still benefit from the activating inductive effect of an electronegative nitrogen atom attached to the amide nitrogen. If alkylidenation of acyl hydrazides could be established, then the expected initial products would be the enehydrazines $\mathbf{5}$, which are the normal intermediates in the Fischer indole synthesis (Scheme 1).

\footnotetext{
* Corresponding author. Tel.: +44 0141548 2389; fax: +44 01415484246

E-mail address: john.murphy@strath.ac.uk (J.A. Murphy).
}

This approach to indoles could have significant benefits, since it would take advantage of the key property of the Wittig reaction in defining the position of the alkene in enehydrazine $\mathbf{5}$. As alluded to above, the major drawback of the normal acid-catalysed Fischer indole synthesis is the reversible tautomerism of the enehydrazine; where the enehydrazine is derived from a fully enolisable ketone, this tautomerism leads to mixtures of regioisomers at the enehydrazine stage, and therefore ultimately results in a regioisomeric pair of indoles.

To test the reactivity of acyl hydrazides towards phosphorus ylides, a range of hydrazides were prepared in straightforward manner as shown below (Scheme 2) from the corresponding acids

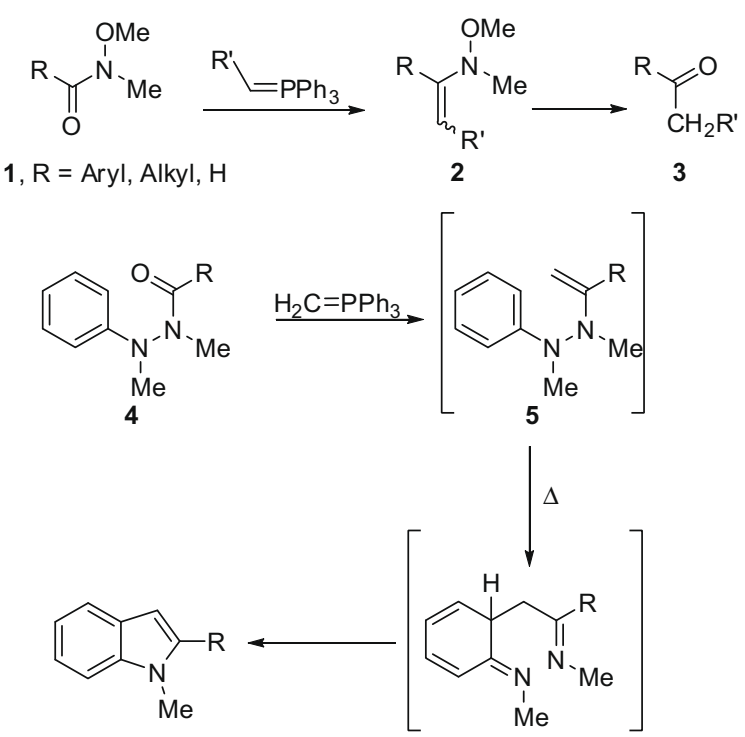

Scheme 1. 


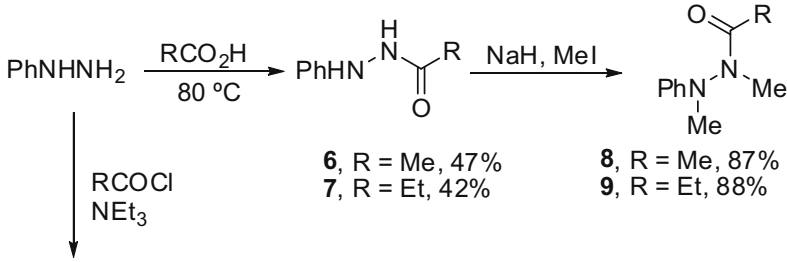<smiles>[R]C(=O)NNP</smiles>

$10, \mathrm{R}=\mathrm{Ph}, 77 \%$

$11, R=2$-furyl, $55 \%$

12, $R=3$-pyridyl

13, $\mathrm{R}=2$-methylpropeny

$14, \mathrm{R}=$ cyclohexyl

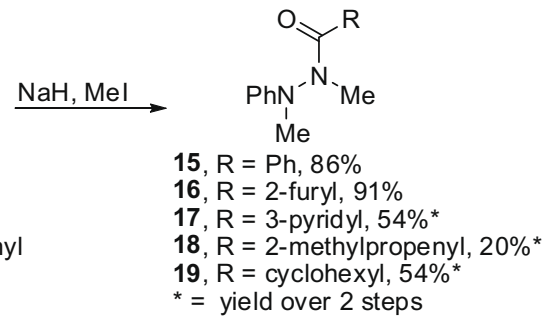

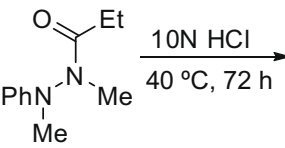

9

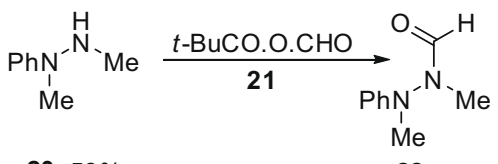

$20,58 \%$

Scheme 2. or acid chlorides. The synthesis of the formyl derivative $\mathbf{2 2}$ used a different approach; hydrolysis of the $N$-propionyl hydrazide $\mathbf{9}$ afforded the dimethylphenylhydrazine $\mathbf{2 0}$-this was reacted with formic pivalic anhydride $\mathbf{2 1}$ to afford the desired product $\mathbf{2 2}$ in $78 \%$ yield.

The reaction of methylenetriphenylphosphorane with the $\mathrm{N}$ benzoylhydrazide $\mathbf{1 5}$ afforded 2-phenylindole $\mathbf{2 3}$ in good yield (78\%). This was followed by equally successful reactions to form the 2-(2-furyl)indole $\mathbf{2 4}$ and the 2-(3-pyridyl)indole 25, thereby showing equal success with electron-rich and electron-poor aroyl hydrazides. Further studies were undertaken with the benzoyl hydrazide 15. Attempts to form 2-phenyl-3-alkylindoles were unsuccessful. Reaction of $\mathbf{1 5}$ with $n$-butylidenetriphenylphosphorane and 3-phenylpropyl idenetriphenylphosphorane led simply to recovery of starting hydrazide $\mathbf{1 5}$ in high yield (70\% and $96 \%$, respectively).

The formyl hydrazide $\mathbf{2 2}$ provided opportunities to form 3-substituted indoles, and towards this end, this substrate was reacted with alkylidenetriphenylphosphoranes. Reaction with $n$-butylidenetriphenylphosphorane and 3-phenylpropylidenetriphenylphosphorane afforded the corresponding 3-alkylindoles 26 (41\%) and 27 (46\%), respectively (Scheme 3).

Extending the reactions to the $N$-acetylhydrazide 8 produced an unexpected result (Scheme 4). Here, $N$-methylindolin-2-one 32 was isolated in $76 \%$ yield. The analogous product $\mathbf{3 3}$ was formed

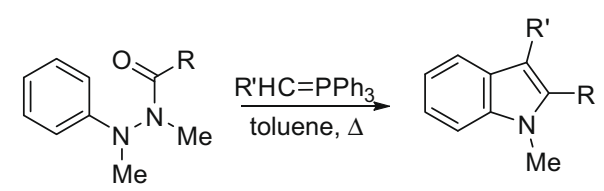

15, $\mathrm{R}=\mathrm{Ph}$

16, $R=2$-furyl

17, $R=3$-pyridyl

23, $\mathrm{R}=\mathrm{Ph}, \mathrm{R}^{\prime}=\mathrm{H}, 78 \%$

$22, \mathrm{R}=\mathrm{H}$

24, $R=2$-furyl, $R^{\prime}=H, 77 \%$

25, $\mathrm{R}=3$-pyridyl, $\mathrm{R}^{\prime}=\mathrm{H}, 78 \%$

26, $\mathrm{R}=\mathrm{H}, \mathrm{R}^{\prime}=\operatorname{Pr}, 41 \%$

27, $\mathrm{R}=\mathrm{H}, \mathrm{R}^{\prime}=\mathrm{CH}_{2} \mathrm{CH}_{2} \mathrm{Ph}, 46 \%$

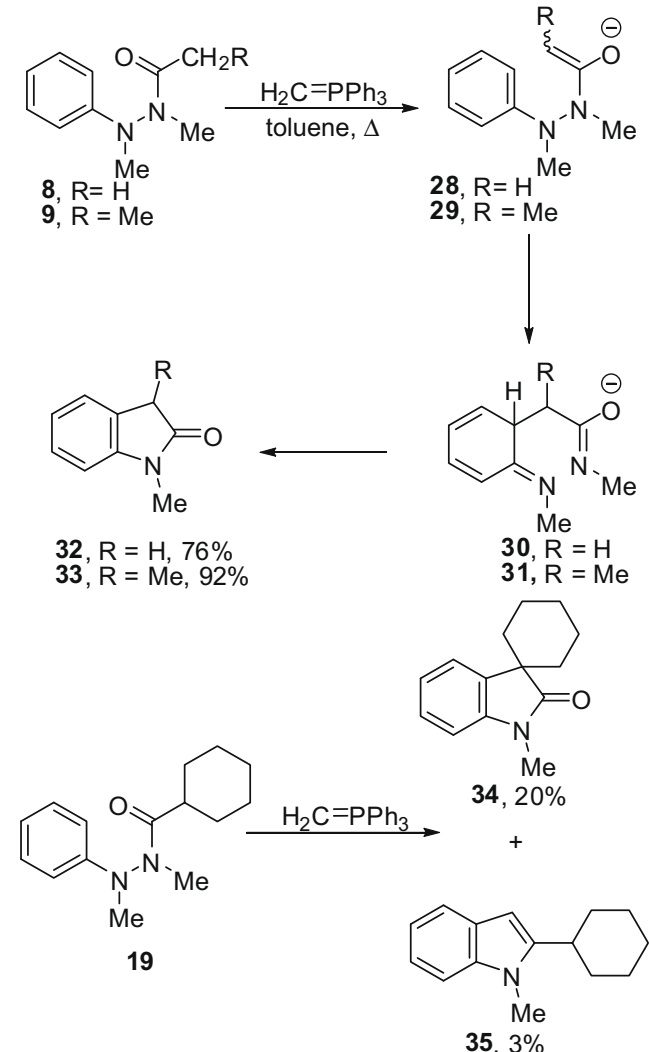

Scheme 4.

(92\%) when the $N$-propionyl hydrazide 9 was reacted. In these cases, the phosphorane clearly shows its basic character and deprotonates $\mathbf{8 / 9}$ to form the enolate of the hydrazide $\mathbf{2 8} / \mathbf{2 9}$. These undergo a Brunner indolin-2-one synthesis, ${ }^{11,12}$ in high yield, to afford 30/31 before condensation to the final products. Basicity of phosphoranes had been observed previously, ${ }^{13-15}$ but to our knowledge, this is the first report of indolin-2-one synthesis using a phosphorane. Our ultimate wish was to find a neutral equivalent of the Fischer indole synthesis, and these reactions clearly show that phosphoranes are deficient in this respect.

The reactivity of cyclohexyl hydrazide 19 mirrored that of the acetyl case 8 , and produced the spiroindolin-2-one 34 (20\%) as well as a low yield of indole 35 (3\%). Clearly, the reactivity of amides with 'enolisable' acyl hydrazides poses a problem for the Wittig reagents.

3-Methylbut-3-enoyl hydrazide 18 behaved differently, however, affording the homologated indolin-2-one 39 (Scheme 5). We propose that this results from conjugate addition of the phosphorane to the $\alpha$, $\beta$-unsaturated hydrazide $\mathbf{1 8}$ to afford $\mathbf{3 6}$ followed by expulsion of triphenylphosphine. The resulting cyclopropane $\mathbf{3 7}$ then undergoes either base-induced deprotonation of one of the gem-dimethyl groups in tandem with ring-opening of the cyclopropane to form the enolate $\mathbf{3 8}$, or thermal prototropic formation of the enol that is equivalent to $\mathbf{3 8}$, followed by deprotonation. The enolate $\mathbf{3 8}$ then undergoes a Brunner reaction to the indolin-2one product 39.

Our reason for proposing the cyclopropane intermediate $\mathbf{3 7}$ stems from isolation of an analogous cyclopropane 41 (42\%) in the reaction of isopropylidenetriphenylphosphorane with Weinreb amide 40. Product 41 shows that gem-dimethylcyclopropanes can result from reaction between phosphoranes and $\alpha, \beta$-unsaturated amides, although the gem-dimethyl group results from different reactants in each of the two cases. 

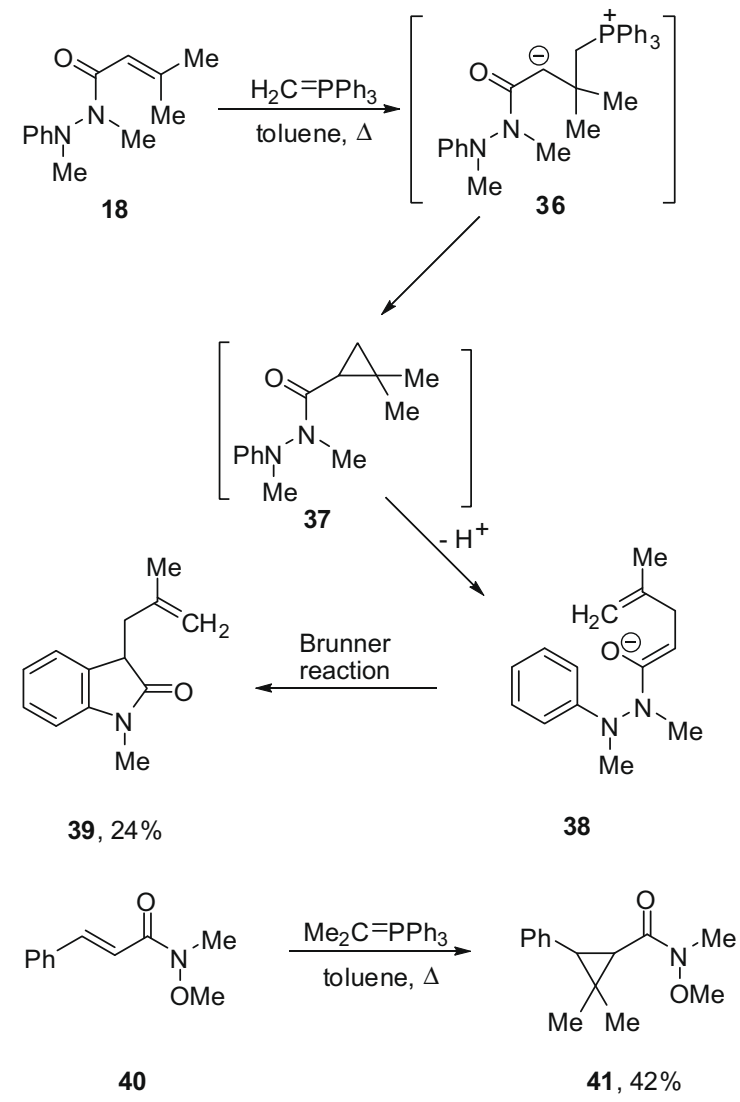

Scheme 5.

From the outcomes of the reactions of phosphoranes with the alkyl substrates, it is clear that the phosphoranes act as strong bases with these 'enolisable' hydrazides. In the development of alkylidenation reactions, titanium-based reagents were developed at least partly to avoid this base property of phosphoranes, and accordingly, we examined the Petasis reagent ${ }^{16,17}$ as a non-basic equivalent for the preparation of 2-alkylindoles and 2-arylindoles.

The difference of reactivity from the phosphoranes was dramatically illustrated on reacting the acetylhydrazide $\mathbf{8}$ (Scheme 6). This now afforded 1,2-dimethylindole $\mathbf{4 2}$, in contrast to the outcome with methylenetriphenylphosphorane. With the titanium reagent, there was no trace of the indolone product $\mathbf{3 2}$ that would arise from the Brunner reaction. Thus, this appears to be an effectively neutral equivalent of the Fischer indole synthesis. Scheme 6 represents the outcomes of initial efforts to afford indoles using the Petasis reagent. Optimisation of the reaction conditions for the alkylidenations and further investigation of the scope of this route for indole preparation are now warranted.

We were keen to probe for evidence of proton abstraction in the acyl group, so the trideuteroacetyl hydrazide $\mathbf{4 4}$ was prepared and

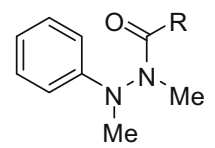

8, $\mathrm{R}=$ methyl

9, $R=$ ethyl

15, $R=$ phenyl

16, $\mathrm{R}=2$-furyl

17, $R=3$-pyridyl

44, $\mathrm{R}=\mathrm{CD}_{3}$

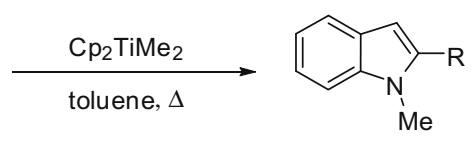

42, $\mathrm{R}=$ methyl, $53 \%$

43, $\mathrm{R}=$ ethyl, $47 \%$

23, $\mathrm{R}=$ phenyl, $48 \%$

24, $R=2$-furyl, $8 \%$

25, $R=3$-pyridyl, $38 \%$

45, $\mathrm{R}=\mathrm{CD}_{3}, 47 \%$ reacted with the Petasis reagent. ${ }^{1} \mathrm{H}$ NMR spectroscopic analysis of 45 revealed no diminution of the one-proton integral at $\mathrm{C}-3$, and retention of $85 \%$ of deuterons on the methyl group at the 2-position in 45. Isotopomers $\left(\mathrm{CHD}_{2}, \mathrm{CH}_{2} \mathrm{D}\right.$ and $\left.\mathrm{CH}_{3}\right)$ were observed, probably due to exchange caused by hydrochloric acid (2 M) during the work-up. ${ }^{2} \mathrm{D}$ NMR spectroscopic analysis confirmed the absence of deuteration at C-3. A selectively deuterated product would not have been available from the conventional Fischer indole synthesis with labelled acetone. Consequently, our method can be used for regioselective labelling of indole products.

Typical procedure for the synthesis of indoles: A solution of titrated methyllithium in diethyl ether $(1.58 \mathrm{M}, 4.4 \mathrm{~mL}, 6.95 \mathrm{mmol}$, 4.8 equiv) was added slowly to a suspension of bis(cyclopentadienyl)titanium dichloride ( $770 \mathrm{mg}, 3.09 \mathrm{mmol}, 2.2 \mathrm{equiv}$ ) in toluene $(5 \mathrm{~mL})$ at $-5{ }^{\circ} \mathrm{C}$ over $15 \mathrm{~min}$. The mixture was stirred for $1 \mathrm{~h}$ at $-5^{\circ} \mathrm{C}$, then for $1 \mathrm{~h}$ at rt. The mixture was cooled to $0^{\circ} \mathrm{C}$, and quenched carefully by addition of an ice-cold $6 \%$ aqueous ammonium chloride solution $(10 \mathrm{~mL})$. The phases were separated, and the organic phase was washed with water $(10 \mathrm{~mL})$, brine $(10 \mathrm{~mL})$, dried over sodium sulfate, filtered, and the solvent was removed in vacuo, until the solution had been reduced to one-third of the original volume, and then toluene $(5 \mathrm{~mL})$ was added. The solution of dimethyltitanocene in toluene was transferred via cannula to a solution of $N$-(3,3-dimethylacryloyl)- $N, N^{\prime}$-dimethyl- $N^{\prime}$-phenylhydrazine 18 (256 mg, $1.44 \mathrm{mmol}, 1.0$ equiv) in toluene $(5 \mathrm{~mL})$. The mixture was then heated at reflux for $72 \mathrm{~h}$. The solvent was removed in vacuo and diethyl ether $(25 \mathrm{~mL})$ was added. The mixture was then filtered through Celite ${ }^{\circledR}$, which was washed with additional diethyl ether $(25 \mathrm{~mL})$. The organic phase was washed with hydrochloric acid $(2 \mathrm{M}, 3 \times 25 \mathrm{~mL})$. The combined aqueous layers were washed with diethyl ether $(2 \times 25 \mathrm{~mL})$, and the combined organic phase was dried over sodium sulfate, filtered, and the solvent was removed in vacuo. The crude mixture was finally purified by column chromatography (hexanes-diethyl ether, 98:2) to afford 1,2-dimethylindole 42 (110 mg, 53\%). Mp 53-54 ${ }^{\circ} \mathrm{C}$, (lit., ${ }^{18} 54-$ $\left.55^{\circ} \mathrm{C}\right)$; [Found: $[\mathrm{M}]^{+}\left(\mathrm{EI}^{+}\right)$145.0886, $\mathrm{C}_{10} \mathrm{H}_{11} \mathrm{~N}$ requires $[\mathrm{M}]^{+}$, 145.0886]; $v_{\max }(\mathrm{KBr}) / \mathrm{cm}^{-1} 3047(\mathrm{Ar}-\mathrm{H}), 2988(\mathrm{C}-\mathrm{H}), 1605(\mathrm{C}=\mathrm{C})$; $\delta_{\mathrm{H}}\left(400 \mathrm{MHz}, \mathrm{DMSO}-\mathrm{d}_{6}\right) 2.40\left(3 \mathrm{H}, \mathrm{d}, J \mathrm{~J}, 7, \mathrm{CH}_{3}\right), 3.65\left(3 \mathrm{H}, \mathrm{s}, \mathrm{CH}_{3}\right)$, $6.20(1 \mathrm{H}$, br s, Ar-H), 6.94-6.98 $(1 \mathrm{H}, \mathrm{m}, \mathrm{Ar}-\mathrm{H}), 7.03-7.08(1 \mathrm{H}, \mathrm{m}$, Ar-H), 7.34-7.36 (1H, m, Ar-H), 7.41-7.42 (1H, m, Ar-H); $\delta_{\mathrm{C}}$ (100 MHz, DMSO-d $\left.)_{6}\right) 13.3\left(\mathrm{CH}_{3}\right), 30.1\left(\mathrm{CH}_{3} \mathrm{~N}\right), 100.0(\mathrm{CH}), 110.0$ (CH), $119.7(\mathrm{CH}), 120.0(\mathrm{CH}), 120.9(\mathrm{CH}), 128.4(\mathrm{C}), 131.9(\mathrm{C})$, $137.9(\mathrm{C}) ; \mathrm{m} / z\left(\mathrm{EI}^{+}\right) 145\left([\mathrm{M}]^{+}, 100 \%\right), 144\left([\mathrm{M}-\mathrm{H}]^{+}, 100\right)$.

\section{Acknowledgements}

We thank the EPSRC and WestCHEM for funding, and EPSRC National Mass Spectrometry Service, Swansea, for mass spectral analysis.

\section{Supplementary data}

Supplementary data (preparation of acyl hydrazides, synthesis of indoles using the Petasis reagent and its reactions with alkylidene triphenylphosphoranes) associated with this article can be found, in the online version, at doi:10.1016/j.tetlet.2009.02.060.

\section{References and notes}

1. For reviews of indole syntheses: (a) Joule, J. A.. In Science of Synthesis; Thomas, E. J., Ed.; Thieme: Stuttgart, 2000; Vol. 10, pp 361-652; (b) Gilchrist, T. L. J. J. Chem. Soc., Perkin Trans. 1 1999, 2849-2866; (c) Gribble, G. W. J. Chem. Soc., Perkin Trans. 1 2000, 1045-1075.

2. More recent syntheses of indoles include: (a) Rutherford, J. L.; Rainka, M. P.; Buchwald, S. L. J. Am. Chem. Soc. 2002, 124, 15168-15169; (b) Kamijo, S.; Yamamoto, Y. Angew. Chem., Int. Ed. 2002, 41, 3230-3233; (c) Arisawa, M.; Terada, Y.; Nakagawa, M.; Nishida, A. Angew. Chem., Int. Ed. 2002, 41, 47324734; (d) Smith, A. B.; Kano, N.; Ishiyama, H.; Minikawa, N.; Rainier, J. D.; Hartz, 
R. A.; Cho, Y. S.; Cui, H.; Moser, W. H. J. Am. Chem. Soc. 2003, 125, 8228-8237 (e) Siebeneicher, H.; Bytschkov, I.; Doye, S. Angew. Chem., Int. Ed. 2003, 42, 3042-3044; (f) Shimada, T.; Nakamura, I.; Yamamoto, Y. J. Am. Chem. Soc. 2004 126, 10546-10547; (g) Willis, M. C.; Brace, G. N.; Holmes, I. P. Angew. Chem., Int Ed. 2005, 44, 403-406; (h) Baran, P. S.; Guerrero, C. A.; Ambhaikar, N. B.; Hafensteiner, B. D. Angew. Chem., Int. Ed. 2005, 44, 606-609; (i) Herzon, S. B. Myers, A. G. J. Am. Chem. Soc. 2005, 127, 5342-5344; (j) Dunetz, J. R.; Danheiser R. L. J. Am. Chem. Soc. 2005, 127, 5776-5777; (k) Taber, D. F.; Tian, W. J. Am. Chem. Soc. 2006, 128, 1058-1059; (1) Alex, K.; Tillack, A.; Schwarz, N.; Beller, M. Angew. Chem., Int. Ed. 2008, 47, 2304-2307; (m) Cui, S. L.; Wang, J.; Wang, Y.-G. J. Am. Chem. Soc. 2008, 130, 13526-13527.

3. Fischer, E.; Jourdan, F. Chem. Ber. 1883, 2241-2245.

4. Fischer, E.; Hess, O. Chem. Ber. 1884, 559-568.

5. For leading recent work on the Fischer indole reaction, see: Wagaw, S.; Yang, B. H.; Buchwald, S. L. J. Am. Chem. Soc. 1999, 121, 10251-10263.

6. (a) Simoneau, C. A.; Ganem, B. Tetrahedron 2005, 61, 11374-11379; (b) Christoffers, J. Synlett 2006, 318-320; (c) Diedrich, C. L.; Frey, W.; Christoffers, J. Eur. J. Org. Chem. 2007, 4731-4737.

7. Murphy, J. A.; Commeureuc, A. G. J.; Snaddon, T. N.; McGuire, T. M.; Khan, T. A. Hisler, K.; Dewis, M. L.; Carling, R. Org. Lett. 2005, 7, 1427-1429.
8. Hisler, K.; Tripoli, R.; Murphy, J. A. Tetrahedron Lett. 2006, 47, 6293.

9. Murphy, P. J.; Lee, S. E. J. Chem. Soc., Perkin Trans. 1 1999, 3049-3066.

10. Murphy, P. J.; Brennan, J. Chem. Soc. Rev. 1988, 17, 1-30.

11. Robinson, B. The Fischer Indole Synthesis; John Wiley \& Sons: Chichester, 1982

12. (a) Brunner, K. Monatsh. Chem. 1896, 17, 479-549; (b) Brunner, K. Monatsh. Chem. 1897, 18, 95-122; (c) Moore, R. F.; Plant, S. G. P. J. Chem. Soc. 1951, 34753478; (d) Schwarz, H. Monatsh. Chem. 1903, 24, 568-578; (e) Stanek, J. Chem. Listy 1943, 37, 161-166; (f) Wenkert, E.; Bhattacharyya, N. K.; Reid, T. L.; Stevens, T. E. J. Am. Chem. Soc. 1956, 78, 797-801; (g) Endo, Y.; Uchida, T.; Shudo, K. Tetrahedron Lett. 1997, 38, 2113-2116.

13. Marshall, J. A.: Pike, M. T.; Carroll, R. D. J. Org. Chem. 1966, 31, 2933-2941.

14. Heathcock, C. H.; Ratcliffe, R. J. Am. Chem. Soc. 1971, 93, 1746-1757.

15. Lombardo, L. Tetrahedron Lett. 1982, 23, 4293-4296.

16. Petasis, N. A.; Bzowej, E. I. J. Am. Chem. Soc. 1990, 112, 6392-6394.

17. For the recent use of titanium carbenes in indole synthesis, see: Main, C. A.; Petersson, H. M.; Rahman, S. S.; Hartley, R. C. Tetrahedron 2008, 64, 901914.

18. McDonald, B. G.; Proctor, G. R. J. Chem. Soc., Perkin Trans. 1 1975, 14461450 . 